\title{
¿Los padres educan a sus hijos y los abuelos malcrían a sus nietos?
}

\author{
Parents raise their children and grandparents spoil their grandchildren? \\ Os pais educam os filhos e os avós mimam os netos?
}

Recibido: 13/01/2022 | Revisado: 17/01/2022 | Acepto: 18/01/2022 | Publicado: 20/01/2022

\author{
Joan Tahull Fort \\ ORCID: https://orcid.org/0000-0002-4791-1704 \\ Generalitat de Catalunya. Departament d'Educació, Espanha \\ Universitat de Lleida, Espanha \\ E-mail: joan.tahull@udl.cat \\ Yolanda Montero Plaza \\ ORCID: https://orcid.org/0000-0001-8878-6789 \\ Generalitat de Catalunya. Departament d'Educació, Espanha \\ E-mail: ymontero@xtec.cat
}

\begin{abstract}
Resumen
En los últimos años en los países occidentales, también en España, está aumentado el cuidado intensivo de los abuelos hacia sus nietos. La mujer ha salido de casa y el hombre no ha entrado y este espacio ha sido ocupado por los abuelos, principalmente para atender a los menores. Parece que estos infantes tienen déficits en aspectos como: pérdida del sentido de la autoridad, límites y reglas difusas, confusión de roles, baja autoestima... Para la realización de la investigación se presentan datos cuantitativos oficiales y también diferentes entrevistas a personas conocedoras de la temática. La opción de muchos padres de delegar su responsabilidad de cuidado y educación de sus hijos a sus abuelos puede tener consecuencias presentes y futuras perjudiciales para los menores.
\end{abstract}

Palabras clave: Familia; Apego; Abuelo; Padre; Nietos.

\begin{abstract}
In recent years in western countries, also in Spain, the intensive care of grandparents towards their grandchildren has increased. The woman has left the house and the man has not entered and this space has been occupied by the grandparents, mainly to take care of the minors. It seems that these infants have deficits in aspects such as: loss of sense of authority, vague limits and rules, confusion of roles, low self-esteem... In order to carry out the research, we present official quantitative data and also different interviews with people who know the subject. The choice of many parents to delegate their responsibility for the care and education of their children to their grandparents may have present and future detrimental consequences for minors.
\end{abstract}

Keywords: Family; Attachment; Grandfather; Father; Grandchildren.

\begin{abstract}
Resumo
Nos últimos anos, nos países ocidentais, também em Espanha, os cuidados intensivos dos avós para com os seus netos aumentaram. A mulher saiu de casa e o homem não entrou e este espaço foi ocupado pelos avós, principalmente para atender aos menores. Parece que estes infantes têm déficits em aspectos como: perda do sentido da autoridade, limites e regras difusas, confusão de papéis, baixa autoestima... Para a realização da investigação são apresentados dados quantitativos oficiais e também diferentes entrevistas a pessoas conhecedoras da temática. A opção de muitos pais de delegar a sua responsabilidade de cuidar e educar os seus filhos aos avós pode ter consequências presentes e futuras prejudiciais para os menores.
\end{abstract}

Palavras-chave: Família; Apego; Avô; Pai; Netos.

\section{Introducción}

En los últimos años en los países occidentales se han producido cambios sociales, culturales y económicos muy relevantes; transformando estructuras, dinámicas e identidades. Una de las instituciones con unos cambios más visibles y drásticos ha sido la familia, modificando conductas y roles de lossujetos. Progresivamente los hogares han reducido sus miembros, hay múltiples tipologías familiares (las cuales se transforman rápidamente) y también la masiva y rápida incorporación de la mujer al espacio público. Además la no superación para todos de la crisis económica. Comprender este cambio de paradigma es multifactorial, están imbricadas múltiples dimensiones (social, cultural, económica, psicológica, religiosa...). Abordar la complejidad está fuera del alcance de la investigación. El presente artículo quiere analizar un ámbito 
concreto de estos cambios acaecidos en los últimos tiempos: mostrar, analizar y contrastar la incorporación de los abuelos en el cuidado de sus nietos y sus posibles consecuencias para los infantes en el presente y futuro.

El artículo tiene el objetivo de describir y reflexionar sobre la evolución de las familias españolas y catalanas, concretamentelas causas y motivaciones del incremento de horas de cuidado de los abuelos hacia sus nietos. Analizar si este cuidado es intensivo o parcial (o voluntario) y las posibles consecuencias presentes y futuras para los menores. Conocer el porcentaje de padres-madres que utilizan los abuelos para cuidar intensivamente de sus hijos; también, se muestran gráficos cuantitativos sobre las horas de cuidado de los abuelos a los nietos y el porcentaje de cuidadores. Estos datos se complementan con reflexiones de vivencias de personas conocedoras de esta realidad social, con15 entrevistas en profundidad (maestros, abuelas e hijos mayores de edad) de Barcelona y Lleida conocedores de la temática; presentan posibles consecuencias o limitaciones del cuidado intensivo.

Señalar la escasez de estudios relevantes sobre el cuidado de los abuelos a los nietos desde la perspectiva de los menores. Hay una amplia bibliografía sobre la tercera edad, centenarios, jubilación, cuidado del abuelo a los nietos desde la perspectiva de los mayores...; por el contrario, hay pocas investigaciones sobre las consecuencias y repercusiones a los niños. Esta temática está poco abordada y aquellos estudios realizados presentan una visión romántica del amor y ternura recíproco entre el abuelo y el nieto; también la admiración del nieto hacia el abuelo. Esta investigación pretende llenar humildemente un vacío y abrir futuras vías de análisis en las ciencias sociales. Se parte de la hipótesis que la incorporación masiva e intensa de los abuelos al cuidado de los nietos puede tener en algunos casos consecuencias negativas hacia los mayores de edad pero también implicaciones perjudiciales y poco tenidas en cuenta para el desarrollo presente y futuro del infante.

\section{Fundamentos Teóricos}

En los últimos años se han producido cambios significativos en las sociedades avanzadas, aumentando la complejidad de las estructuras sociales y produciendo situaciones de incertidumbre, complejidad, dudas, fragmentación y cambios constantes para los sujetos (Tahull et al., 2019).A raíz de la crisis económica aparecida en el 2008 de la cual todavía se observan sus consecuencias en múltiples dimensiones sociales, Allepuz et al.(2014:172) destaca que "en España ha disminuido el riesgo de pobreza de los jubilados y ha aumentado significativamente para los menores de edad. (...) La pobreza infantil es uno de los datos más preocupantes de la situación social actual y de futuro". Los abuelos están siendo el sostén económico, emocional y social en muchos hogares españoles. Bowlby (1998, 2006 y 2009) destaca la importancia del apego para la construcción de la personalidad de los infantes; en la niñez, adolescencia y juventud; necesitan un regazo seguro, un espacio propio y estable, lejos de los azares, arbitrariedades y peligros exteriores. La figura materna y paterna es fundamental para la construcción de la personalidad de los niños.

La familia se ha transformado en los últimos años, pasando de modelos tradicionales y estables, hacia estructuras más diversas y múltiples, con menos miembros y grupos más líquidos y cambiantes. Tal como señala Elzo (2006 y 2008$)$ se ha producido un proceso de alejamiento de los padres de la educación de sus hijos; por diversas circunstancias principalmente por las expectativas de los padres hacia su propio bienestar social, dice "las señales de alarma para la familia se han puesto en rojo" (p.39); también, siguiendo con el autor vasco, la incorporación de la mujer al mercado laboral sin que el hombre haya entrado en el hogar; afirma "la familia está en un proceso de cambio vertiginoso, y nos encontramos ante muchos hijos únicos en el seno del hogar en el que la mujer ha salido de casa sin que el hombre haya entrado" (p.76).

Paralelamente a los cambios acaecidos en los hogares de las sociedades avanzadas, también en España, se ha producido un aumento de la esperanza de vida de las personas. La llegada a la jubilación ya no significa proximidad de la muerte sino el inicio de una nueva y larga vida; también los abuelos y nietos llegan a convivir juntos durante más tiempo.Para Mejías y 
Research, Society and Development, v. 11, n. 2, e12511225686, 2022

(CC BY 4.0) | ISSN 2525-3409 | DOI: http://dx.doi.org/10.33448/rsd-v11i2.25686

Ballesteros (2011) el fenómeno de los abuelos y abuelas cuidadores de nietos es general en Europa, también en España, aunque se presenta con más intensidad, dedicación y responsabilidad en las familias españolas. Según Ricis (2017), citando a León et al. (2016), los abuelos realizan las funciones de cuidadores cuando los padres salen del hogar, entoncesse convierten en los máximos responsables del cuidado y educación de sus nietos. Arpino et al. (2018) destacan que los abuelos tienen más bienestar subjetivo cuando cuidan de sus nietos de forma no intensiva; también los abuelos cuidadores tienen más bienestar subjetivo que aquellos no cuidadores. Para Arpino et al. (2017) el cuidado intenso de los abuelos a sus nietos conlleva la reducción de la participación en actividades sociales (voluntariado, educación, participación políticas...) relacionadas con la comunidad.

Caballero Guisado (2015) destaca que la clase social tiene una relación directa con las diferentes posibilidades de cuidado de los abuelos a sus nietos. Los abuelos cuidadores de clases sociales más bajas se sienten más "utilizados" por sus hijos, en muchas situaciones se definen como "esclavos"; por el contrario, aquellos de clases sociales más altas gozan de un tiempo de más calidad y disfrute; en muchos casos afirman que pasarían más tiempo con sus nietos. Se producen unas diferencias en las calidades de las relaciones y tiempos por clases sociales. Para Mari-Klose et al.(2015) la crisis económica ha multiplicado la necesidad de cuidado de los abuelos hacia sus nietos; también se ven obligados a realizar transferencias monetarias mensuales y ayudar en lo necesario.

Tradicionalmente se consideraba la vejez como un tiempo vivido por unos individuos especiales, con unos conocimientos y experienciasúnicas entre todos los miembros de la comunidad. Tenían una sabiduría intrínseca por la vida vivida que debía ser transmitida a la sociedad, familia y nietos; ellos eran los guardianes y comunicadores de la historia y recuerdos de la comunidad y la familia (Beauvoir, 1983). Desde siempre, la relación entre los abuelos y los nietos ha estado impregnada por el amor, la confianza y el cariño; en cambio, las relaciones entre los padres e hijos estaban condicionadas por las reglas, normas y limitaciones. Los padres educaban y formaban a sus hijos, era su función tradicionalmente reconocida. El rol de los abuelos estaba asociado a lo emocional y menos a lo autoritario; se aceptaba y reforzabasocialmente que los abuelos mimasen a sus nietos (Ricis, 2017).

Diferentes estudios abordan las consecuencias negativas de un abuso de las horas de cuidado de las abuelas a sus nietos. Para Aguayo et al. (2013), Caballero Guisado (2015) y Luna et al.(2016) ejercer estas funciones parentales por los abuelos representa cambios drásticos en su cotidianidad. Los abuelos afirman tener poca libertad, problemas de salud, poca independencia, problemas psicológicos, cambios desus amistades, problemas económicos, vivienda poco adecuada para el cuidado, no tener las energías y convicciones suficientes para cuidar y educar adecuadamente... Por Fernández (2016) y Rald Philipp (2007) demasiados abuelos son "padres sustitutos", realizan tareas propias de los padres, no de los abuelos; en estos casos genera ansiedad y estrés a los abuelos pero también frena el desarrollo social y pedagógico de los niños: pérdida del sentido de la autoridad, límites y reglas difusas,confusión de roles, menor autoestima...Baderasy López (2011) relacionan cuidado intensivo de los abuelos a los nietos con carencias sociales y pedagógicas relevantes de los infantes, sin concretar el número de horas.

Según la Encuesta de Salud, Envejecimiento y Jubilación en Europa (SHARE) del año 2016, en España, aproximadamente un $25 \%$ de los abuelos cuida cada día una media de siete horas diarias de sus nietos durante todo el año. En estas familias los abuelos son el último sostén psicológico y económico y también referentes para sus nietos; sin su intensa colaboración muchos hogares zozobrarían. Para el correcto desarrollo de todas las dimensiones del menor los miembros de la familia deberían realizar las funciones que les corresponde. Los abuelos deberían ser abuelos y los padres ser padres.

\section{Metodología}

Para la realización del artículo se ha utilizado información cuantitativa de la encuesta europea SHARE, también se han utilizado datos del Instituto Nacional de Estadística (INE), para tener una visión más detallada de España. Se ha obtenido 
Research, Society and Development, v. 11, n. 2, e12511225686, 2022

(CC BY 4.0) | ISSN 2525-3409 | DOI: http://dx.doi.org/10.33448/rsd-v11i2.25686

información de las horas semanales de cuidado de los abuelos a sus nietos y diferentes ítems relevantes. Además se han introducido datos de la encuesta Mémora, sobre la existencia del fenómeno de los "abuelos/as esclavos".

Se ha complementado con información cualitativa, para completar y describir situaciones concretas significativas. Se han realizado 15 entrevistas en profundidad: 5 maestros/as, 5 abuelos/as y 5 hijos/as (en la actualidad mayores de edad). Se considera valioso realizar las entrevistas a los jóvenes mayores de edad por no tener la limitación de la autorización paterna y también ellos presentan una explicación más reflexiva de la situación personal vivida. Se buscaron informantes que pudieran ofrecer una mirada concreta, específica y significativa. Todos los informantes son de la Comunidad Autónoma de Cataluña, siendo todos ellos de Lleida ciudad y pueblos cercanos y Barcelona ciudad y localidades próximas. Se han buscado informantes siguiendo diferentes criterios: rural/urbano, hombre/mujer, diferentes edades, clases sociales diversas... Todos los informantes son anónimos, no son personas conocidas públicamente pero son conocedoras de la temática estudiada y han presentado en todos los casos información relevante.

Se han entrevistado a 5 maestras de infantil y primaria de Barcelona ciudad y localidades cercanas y de Lleida ciudad. Maestros de centros públicos. Se ha contactado con los informantes por amistades o conocidos. Nos hemos desplazado a su localidad y hemos realizado las entrevistas en su casa o en un lugar público. Las entrevistas se han grabado, con su consentimiento, y se han transcrito solamente las partes más significativas; aquellas susceptibles de ser utilizadas en la investigación. Además se han entrevistado a 5 abuelos/abuelas, de Barcelona y Lleida y pueblos cercanos. Se han presentado situaciones sociales muy diferentes, desde una mirada metropolitana y otras rural. Las familias son de clases sociales diferentes, desde clases sociales más bajas, con dificultades económicas, hasta alguna de clase media y media alta, propietarios de un negocio con 30 trabajadores. Los investigadores hemos podido comprobar las diferencias y matices sobre las relaciones y rutinas entre los abuelos y nietos. También se han realizado 5 entrevistas a jóvenes, algunos estudiantes de titulaciones posobligatorias y otros trabajando. Todos son mayores de edad y han explicado, reflexionado y analizado sus vivencias y relaciones hacia sus abuelos y padres.

En todas las investigaciones sociales se presenta la limitación de la subjetividad, para acercarse a analizar y describir la realidad social de forma objetiva. Se han priorizado aquellas reflexiones y vivencias particulares más representativas de la generalidad; aquellas más repetidas y reiteradas por los informantes, también por la elaboración y coherencia del discurso elaborado. Se ha intentado contrastar, comparar y valorar todos los datos para presentar aquellas ideas y opiniones más repetidas y sentidas por los informantes (Stake, 1998; Ander Egg, 2000).

La información obtenida ha sido suficiente aunque siempre limitada. Con una muestra más extensa se hubiese podido afinar más las conclusiones. En todo caso, se ha presentado información relevante y significativa. La triangulación ha sido un elemento fundamental para construir el relato aunque mucha información no aparece en los resultados -también es muy importante para contrastar los datos-, para tener una visión global y más concreta del objeto de estudio planteado.

\section{Resultados}

En este apartado se presentan datos cuantitativos y cualitativos sobre el cuidado de los abuelos hacia sus nietos y se analizan las características de estas relaciones y sus posibles consecuencias. En una primera parte se presentan datos de diferentes fuentes oficiales: Instituto Nacional de Estadística, la Encuesta de Salud, Envejecimiento y Jubilación en Europa y la encuesta de la institución privada Mémora. En la segunda parte se presentan reflexiones y vivencias de individuos conocedores de primera mano de esta temática social, permite contextualizar y describir los datos numéricos.

En la siguiente tabla se presentan datos del Instituto Nacional de Estadística (INE) sobre horas semanales dedicadas a actividades de cuidados y tareas del hogar, en España y en los países de la Unión Europea (28) del año 2016: 
Tabla 1: Horas semanales dedicadas a actividades de cuidado y tareas del hogar. España y EU-28- 2016.

\begin{tabular}{|l|l|l|l|l|}
\multicolumn{2}{l|}{} & \multicolumn{2}{c|}{ España } & \multicolumn{2}{c|}{ UE-28 } \\
\hline & Hombres & Mujeres & Hombres & Mujeres \\
\hline Cuidado o educación hijos & 23 & 38 & 21 & 38 \\
\hline Cuidado o educación nietos & & & 12 & 16 \\
\hline
\end{tabular}

Fuente: Realización propia con datos del INE (2016).

Se muestra información sobre las horas semanales de cuidado o educación de hijos por hombres y mujeres en España y en países europeos. Los hombres españoles cuidan 23 horas semanales y las mujeres 38 horas de media; en los países europeos la media es 21 horas los hombres y 38 horas las mujeres. En relación al cuidado de los nietos por sus abuelos, en España los abuelos y abuelas están respectivamente 16 horas y en los 28 países de la Unión europea 12 horas los abuelos y 16 las abuelas. En España los abuelos están más horas de media que los hombres de la Unión Europea y las mujeres están igual 16 horas. Destacar que son datos generales y representan una media.

A continuación se introduce la tabla sobre la frecuencia semanal de las actividades de cuidados y tareas del hogar, en referencia a España y la Unión Europea (28) del año 2016:

Tabla 2: Frecuencia semanal de las actividades de cuidados y tareas del hogar. España y EU28- 2016.

\begin{tabular}{|c|c|c|c|c|c|c|c|c|}
\hline & \multicolumn{4}{|c|}{ España } & \multicolumn{4}{c|}{ UE-28 } \\
\cline { 2 - 9 } & $\begin{array}{c}\text { Al menos varios días } \\
\text { a la semana }\end{array}$ & \multicolumn{2}{|c|}{ Otro } & $\begin{array}{c}\text { Al menos varios días } \\
\text { a la semana }\end{array}$ & \multicolumn{3}{c|}{ Otro } \\
\cline { 2 - 9 } & Hombres & $\begin{array}{c}\text { Mujere } \\
\text { S }\end{array}$ & $\begin{array}{c}\text { Hombr } \\
\text { es }\end{array}$ & $\begin{array}{c}\text { Mujere } \\
\text { Sombr } \\
\text { es }\end{array}$ & $\begin{array}{c}\text { Mujere } \\
\text { S }\end{array}$ & $\begin{array}{c}\text { Hombr } \\
\text { es }\end{array}$ & $\begin{array}{c}\text { Mujere } \\
\text { s }\end{array}$ \\
\hline $\begin{array}{c}\text { Cuidados o } \\
\text { educación hijos }\end{array}$ & 76 & 95 & 24 & 5 & 80 & 91 & 20 & 9 \\
\hline $\begin{array}{c}\text { Cuidado o } \\
\text { educación de nietos }\end{array}$ & 33 & 32 & 67 & 68 & 21 & 25 & 79 & 75 \\
\hline
\end{tabular}

Fuente: Realización propia con datos del INE (2016).

Un 33\% de los abuelos españoles (al menos varios días a la semana) están con sus nietos y el 32\% de las abuelas. En la Unión Europea, representa el 21\% de los abuelos (al menos varios días a la semana) cuidan a sus nietos y el 25\% de las abuelas. Representa una media que no permite tener una mirada exacta de los diferentes matices y extremos.

En España, según la Encuesta de Salud, Envejecimiento y Jubilación en Europa (SHARE) del año 2016aproximadamente un $25 \%$ de los abuelos cuida cada día una media de siete horas diarias de sus nietos; esta dedicación continúa también los fines de semana. Durante los meses de verano las horas dedicadas por los abuelos a sus nietos aumenta debido al tiempo libre. El estudio muestra como los abuelos son un sostén fundamental para el mantenimiento de la familia y el cuidado de los nietos. Sin su colaboración muchas familias no podrían sostenerse y sus dificultades aumentarían.

La encuesta Mémora (2018) trata sobre los abuelos cuidadores en Cataluña, personas mayores de 60 años que cuidan de sus nietos. Han encuestado a 564 personas mayores de 60 años y casi el 50\% de las personas consideran que existe el concepto del "abuelo esclavo". En los últimos diez años se han cronificado situaciones de dificultades económicas para muchas familias por la no superación completa de la crisis económica; un síntoma de esta situación social y económica son los "abuelos esclavos" en algunas familias. En la próxima tabla se evidencian estos datos: 
Tabla 3: Existencia del fenómeno de "abuelos/as esclavos", valores absolutos y relativos.

\begin{tabular}{|c|c|c|c|}
\hline Existencia de abuelos/abuelas esclavos? & Valor Absoluto & $\begin{array}{c}\text { Valores Relativos } \\
(\%)\end{array}$ & $\begin{array}{c}\text { Valores Relativos } \\
(\%)\end{array}$ \\
\hline No sé qué contestar & 74 & 13,12 & 13,12 \\
\hline $\begin{array}{l}\text { No, porque abuelos y abuelas les toca ayudar a } \\
\text { sus hijos/as }\end{array}$ & 45 & 7,98 & \multirow{2}{*}{38,30} \\
\hline No, porque cuidar a los nietos es un regalo & 171 & 30,32 & \\
\hline $\begin{array}{l}\text { Sí, pero los abuelos y abuelas les toca ayudar a } \\
\text { sus hijos/hijas. }\end{array}$ & 66 & 11,70 & \multirow{3}{*}{48,58} \\
\hline $\begin{array}{l}\text { Sí, porque tienen que cuidar de sus nietos sin } \\
\text { poder escoger }\end{array}$ & 127 & 22,52 & \\
\hline $\begin{array}{l}\text { Sí, porque no tienen tiempo de hacer lo que les } \\
\text { gusta }\end{array}$ & 81 & 14,36 & \\
\hline $\begin{array}{c}\text { TOTAL } \\
\end{array}$ & 564 & 100,00 & 100,00 \\
\hline
\end{tabular}

Nota: Encuesta Mémora (2018).

En general, el 48,6\% de los participantes consideran la existencia de los "abuelos esclavos"; en cambio, el 30,3\% afirman cuidar a los nietos es un regalo. Un 22,5\% de los abuelos consideran que existen "abuelos esclavos"por no poder decidir cuándo cuidar o no, deben hacerlo obligatoriamente; un 14,4\% dejan de hacer otras cosas para cuidar, pierden libertad, y un $11,7 \%$ lo ven como una obligación.

Seguidamente se presentan reflexiones y vivencias de individuos representativos del cuidado de los abuelos hacia sus nietos. Se presentan situaciones concretas significativas para comprender los datos numéricos. Principalmente se hace referencia a las familias que utilizan a los abuelos para cuidar intensivamente a sus nietos. Primero se introducirán las aportaciones de las maestras, después los abuelos y finalmente las reflexiones de los hijos mayores de edad.

Paula de 35 años es maestra de infantil en una escuela pública de una localidad cercana a Barcelona explica:

La mayoría de los niños se quedan todo el día en la escuela, se quedan al comedor y luego en la actividad de la merienda, luego vienen a buscarlos los abuelos. ¡Todo el día en el centro! Yo tampoco lo aguantaría y hay niños que lo hacen desde P-3. ¡Peor que un día de trabajo de los adultos! En la salida como máximo hay tres o cuatro madres, los demás siempre son abuelas o abuelos. ¿Qué carga! ;Algunos vienen todos los días del curso! Hay algún niño que han venido los abuelos a la tutoría, y por supuesto no la hemos realizado hasta que no han venido los padres. Los abuelos de hoy en día tienen una gran responsabilidad al educar a los nietos cuando no les toca. ¡Creo que hacen lo que pueden!', iyalgunos vienen con bastón!...

Veo niños en el parque que hay delante de la escuela que hacen lo que quieren y los abuelos no pueden controlarlos, no tienen los límites establecidos. Es normal, no son sus padres y tampoco tienen la paciencia ni quieren enfrentarse. El parque está lleno de abuelos con sus nietos, ;ha cambiado mucho!, en mi tiempo no pasaba y las madres venían a buscarnos y nos llevaban al parque. Las abuelas y los abuelos están hablando en los bancos y los nietos corriendo arriba y abajo y a veces peleando entre ellos, jsin que nadie diga nada!He estado años trabajando como tutora de infantil y cada vez más me cuesta poner límites, reglas y rutinas al comienzo de curso. Al primer trimestre nos deberían pagar el doble, hago el trabajo que se debería hacer en casa, poner límites y decirles la "palabra no". A muchos niños nadie les han dicho "no" y todo el día están con rabietas.Tienen muy poca tolerancia a la frustración.

Pasan muchas horas con los abuelos y estos no tienen ninguna paciencia, ni capacidad en muchos casos (se están convirtiendo en cuidadores con edades muy avanzadas) para hacerse cargo de dos o tres nietos. jImagínate que ya eres mayor y ahoraque tocaría descansar tienes que cuidar! A mí no me gustaría, un rato vale pero no una obligación de todos los días... No lo sé, creo que todos deberían ser responsables de suscosas. ;Mis padres también tienen unas horas mis hijos, pero trato que sea el mínimo posible porque sino todo está descontrolado!(entrevista realizada el 16 de enero de 2020). 
La maestra explica su experiencia y reflexiones sobre las relaciones entre abuelos y nietos. Muchos niños están todo el día en la escuela, salen después de la merienda y las extraescolares y vienen a buscarlos los abuelos. En las entradas y las salidas del centro educativo la mayoría de adultos son abuelos, una minoría son sus padres. En el parque también la mayoría son abuelas y suceden muchas situaciones de descontrol, "niños corriendo arriba y abajo y a veces peleando entre ellos, ;sin que nadie diga nada!", parece que se naturalizan conductas agresivas y violentas. Los abuelos tienen dificultades para imponer límites, reglas y rutinas a sus nietos; muchos no tienen las fuerzas, interés o capacidades necesarias. En el inicio de curso tiene dificultades para imponer límites y reglas y durante el primer trimestre trabaja rutinas. Piensa que las familias deberían realizar este esfuerzo, principalmente los padres, y no la escuela. Finaliza sus reflexiones explicando que ella como madre también necesita la ayuda de sus abuelos pero es "el mínimo posible porque sino todo está descontrolado". Es consciente de los riesgos de la educación de sus hijos por un cuidado intensiva de los abuelos.

José es maestro de una escuela pública de Lleida ciudad, está en 3r y 4o de primaria y hace 10 años que está en la misma escuela. Explica:

A esta edad muchos niños del barrio ya van y vienen solos ya que los padres no pueden y los abuelos ya no pueden controlarlos. Además ya piensan que son mayores y pueden hacer lo que quieren sin la vigilancia ni control de nadie. A veces nos quedamos por las tardes, los profesores, para hacer reuniones y cuando salimos muchos chicos salen de las actividades extraescolares que se hacen en el centro. En invierno es oscuro a la salida de las extraescolares y vienen los abuelos a buscarlos, a veces les faltan el respeto. Los tratan con imposiciones. ¡Ten!, ;llévame la mochila! Y tiran su mochila a sus abuelos y no dicen ni mu, la cogen y ya está. A veces los abuelos les dicen algo y los chicos dicen, ¡Vale...!, ;Vale...!, ¡No me ralles!, los abuelos dicen, ;se lo diré a tu madre! y ellos dicen... ¡y qué!...

Los abuelos son mayores y se ocupan de sus nietos muchas horas y al final sehacen responsables de la educación de sus nietos. Y estos no valoran nada. Creo que la etapa más dura es la adolescencia, sin normas claras, juf! eso tiene que ser... Si normalmente la adolescencia es una época difícil, imagínate sin normas claras... es una bomba de relojería.

Por una parte los abuelos no han podido o no han sabido poner todas las normas y límites del día a día, porque la educación que dan los abuelos es diferente de las que tienen que dar los padres, y por otra parte, los padres no quieren imponer normas. Con el poco rato que pasan con sus hijos al finalizar el día es más fácil no tenerse que enfadar. Imagínate... vienes cansado y encima te tienes que enfadar para poner límites... pues que hagan lo que quieran que mañana será otro día. Y el problema es éste, que van pasando los días y lo que era una rabieta de pequeño, que hasta hacía gracia, pues cuando se hacen mayores, ya no hace tanta gracia.

$Y$ así es un pescado que se muerde la cola. Es difícil. En la escuela, cada vez más tenemos niños y preadolescentes con dificultades de regulación del comportamiento o de conducta, pero sin ningún trastorno mental que lo justifique. Sólo porque su entorno social y familiar no ha sido capaz de poner normas y límites o los ha puesto de manera poco correcta. Son alumnos que a la mínima se frustran y a veces estas frustraciones se acompañan con agresividad. Es lo que tenemos hoy en día. Y los pobres abuelos hacen lo que pueden, están sobrepasados (entrevista realizada el 12 de enero 2020).

El docente hace referencia a alumnos de 10 y 11 años, estos son más independientes y tienen cerca la adolescencia. En algunos casos no tratan adecuadamente a sus abuelos, les faltan el respeto, les tiran la mochila, "¡Ten!, ¡llévame la mochila! Y tiran su mochila a sus abuelos y no dicen ni mu, la cogen y ya está"; entonces, cuando los abuelos piden respeto responden diciendo, "no me ralles". Explica sobre las dificultades de la adolescencia, siendo una etapa difícil en el desarrollo del infante, al no tener una referencia paterna clara las complicaciones aumentan, dice, "si normalmente la adolescencia es una época difícil, imagínate sin normas claras... es una bomba de relojería".

Los abuelos son los únicos en muchos casos responsables de la educación de los menores y no pueden, no tienen fuerzas para imponerse y marcar reglas y límites. Reflexiona sobre la disparidad de criterios entre padres y abuelos, muchas veces entran en contradicción y los niños son conscientes y se aprovechan. Los padres llegan tarde a casa, están poco tiempo con sus hijos, y 
no tienen ganas de enfadarse, poner límites y ejercer de padres, "y el problema es éste, que van pasando los días y lo que era una rabieta de pequeño, que hasta hacía gracia, pues cuando se hacen mayores, ya no hace tanta gracia".

José va terminando sus reflexiones haciendo referencia a las dificultades de muchos de sus alumnos para regular su "comportamiento o conducta". No tienen un trastorno mental que lo justifique, solamente son causas sociales y familiares. Dinámicas sociales desordenadas y confusas que desorientan a los menores. No pueden superar las pequeñas frustraciones del día a día y responden con violencia y agresividad. Dice que "es lo que tenemos hoy en día", ya que los padres no están y los abuelos están sobrepasados. Con la llegada de la adolescencia, estos jóvenes han perdido el vínculo con su familia (padres) y su referencia principal son sus iguales, el grupo de amigos.

Mireia es una maestra de infantil en una escuela de un pueblo cercano de Lleida, los últimos tres años ha estado en P-3, explica:

Lo que más me está sorprendiendo estos últimos años es que nos vienen niños y niñas sin lenguaje y casi sin comunicación cuando empiezan P-3. Muchos de ellos empiezan a hablar y relacionarse con los demás cuando ha pasado uno o dos cursos. ¡Funcionan cómo niños autistas! y no lo son. Son niños que pasan muchas horas delante de las pantallas, desde que tenían meses. Los abuelos los cuidan y la manera que estén tranquilos, que coman, que se estén quietos... es dándoles los móviles o las tablets. Es un recurso muy fácil, porque todo el mundo tiene móvil.

Pienso que las familias han cambiado mucho de cuando yo era pequeña. Los padres trabajan los dos y llegan tarde a casa, por lo tanto los hijos los tienen los abuelos. Son niños pantalla. No digo que los abuelos tengan la culpa, hacen lo que pueden, pero si el niño llora se le da el móvil y ya está. Nosotros lo vemos en la escuela cada día, es un gran problema. En las tutorías sale mucho este tema, pero las familias no lo ven como un problema, sino como una solución. Además me comentan que como los abuelos ya son grandes y no tienen mucha paciencia si le dan la comida con el móvil, el niño come y así no se enfadan con él. Qué más quieres pedirles a los abuelos, y aún gracias. ¡Da pena!, pero es la sociedad de hoy en día. Padres trabajando hasta la tarde-noche y los niños con los abuelos que bastante hacen con tenerlos, ir a buscarlos a los centros, jugar en los parques...

Después los fines de semana con los padres reproducen las mismas situaciones, porque los niños ya lo han aprendido y sin móvil no quieren comer. Los niños no hablan porque no interaccionan con los demás, no necesitan el lenguaje. Muchos padres no son conscientes hasta que no se lo decimos nosotras o el pediatra (entrevista realizada el 10 de diciembre de 2019).

La docente explica características de sus alumnos de tres años; algunos tienen problemas de comunicación y un lenguaje pobre para relacionarse. Tienen dificultades para hablar con sus iguales y maestras; entonces se relacionan llorando y chillando, dice, "¡funcionan cómo niños autistas! y no lo son". Pasan muchas horas con las pantallas, principalmente las tabletas y móviles, todas las familias los tienen. Los abuelos utilizan el móvil como señuelo; por ejemplo para comer, ducharlo, cambiarlo... y entonces no hay problemas. Mireia define estos infantes como "niños pantalla". Para muchos abuelos, principalmente aquellos que están más horas con sus nietos, el recurso de las pantallas es el más fácil y utilizado, debido a que "los abuelos ya son grandes y no tienen mucha paciencia si le dan la comida con el móvil, el niño come y así no se enfadan con él".

Muchos padres están todo el día trabajando, llegan a casa por la noche, tarde, y están poco tiempo con sus hijos, "da pena"; los abuelos son en muchos casos los únicos responsables de la educación y formación de estos niños. Los fines de semana no se cambian dinámicas, están muy consolidadas, continúan las inercias. Quizás, tal como dice Mireia, los padres no consideran que sea un problema, lo descubren cuando las especialistas se lo explican. Desconocemos si después cambian dinámicas pero creemos que en muchos casos sigue igual. Muchos no tienen alternativas para cambiar formas de hacer.

Terminadas las aportaciones de las maestras se introducen las vivencias y reflexiones de los abuelos, ellos viven estas situaciones en primera persona. María tiene 72 años y es viuda. Vive en un pueblo a 30 quilómetros de Lleida ciudad. Tiene dos hijos y cuatro nietos pequeños, dice: 
Yo vivo en el pueblo, pero estoy una semana aquí y la otra en Lleida. No paro de arriba a abajo todo el día. No tengo tiempo ni para aburrirme y... ¿aún que me encuentro bien que si me pusiera enferma?, ¿no sé qué harían mis hijos? se tendrían que aguantar, supongo.

La semana que estoy aquí estoy con el nieto de aquí, porque sus padres trabajan. Me lo vienen a buscar a las ocho o así de la tarde, desde que tenía tres o cuatro meses. Así que lo estoy criando yo. Y encima, los fines de semana me lo dejan también pues sus padres siempre tienen cosas que hacer. No sé si tienen trabajo o se lo buscan.

La semana que estoy en Lleida, está con los otros abuelos. Esto ha cambiado mucho, antes los padres teníamos a los hijos y no se los dejábamos a nadie. Los padres hacían de padres y los abuelos de abuelos. Ahora parece al revés. A mí me gusta tenerlo un rato, pero cada día y tantas horas... Yo también tengo que hacer cosas, tengo que ir a comprar, a la peluquería... hay meses que no puedo ir ni a cortarme el pelo. Es lo que hay hoy en día, ¿qué quieres hacer? Pues ayudar...

Luego la semana que estoy en Lleida, allí tengo tres, dos gemelas. Además como están separados, una semana están con el padre y otra con la madre. Cuando las tiene mi hijo me hace bajar a mí. ;Acabo loca con los tres! porque uno quiere hacer una cosa, la otra, otra cosa, y asi todo el día. En el pueblo con uno puedo pero con tres... no puedo, no puedo... Y pienso, cuando llegue su padre ya se arreglará con ellos y yo no les digo nada, mientras no se hagan daño...

Así que estoy entretenida, no me puedo aburrir, lo tengo todo organizado por los otros. Yo tengo dos hijos y me ha costado criarlos menos que ahora criar a los nietos, yo ya soy grande. Mis hijos no se dan cuenta que yo me estoy haciendo mayor y no tengo tantas energías, ni paciencia. Los críos necesitan a sus padres que son más jóvenes para que jueguen con ellos. Uno que no se quiere bañar, la otra que no quiere salir de la bañera... a veces me pongo en la cocina y hago ver que no oigo nada... al rato ya viene alguno llorando. Yo les digo que cuando venga su padre ya verá lo que hará. ¿Qué quieres que haga? Así todos los días, una locura. ¿Qué te parece, no puedo estar aburrida? (Entrevista realizada el 10 de noviembre de 2019).

María reside en Lleida y cuida de sus nietos que viven en diferentes localidades. Se desplaza, no lo explica, seguramente en transporte público, en tren o autobús. Se encuentra bien y ayuda en lo que puede pero se pregunta, "¿qué ocurriría si se pusiera enferma?". Ella tiene la responsabilidad del cuidado de sus nietos casi todo el día, cuando no están en la escuela. Sus padres vienen a buscarlos a las 20:00 horas de la tarde, después de toda la jornada, listo para llevarlos a la cama. Afirma rotundamente que está criando a los nietos, "los estoy criando yo". Durante los fines de semana también los cuida, sus padres trabajan o se buscan ocupaciones, desconoce las motivaciones. Parece que los padres no tienen mucho interés en educar y estar con sus hijos. Los padres antes hacían de padres y los abuelos de abuelos, en cambio, actualmente, los padres no están y los abuelos hacen de padres. Dice que le está costando más el cuidado de sus nietos que de sus hijos cuando eran pequeños, actualmente, "no tengo tantas energías, ni paciencia". No lo expresa directamente pero parece que se identifica con la definición de las "abuelas esclavas". Muchas veces, cuando hay algún conflicto no media, no tiene fuerzas y "hago ver que no oigo nada... al rato ya viene alguno llorando". Delega la responsabilidad y mediación hacia sus padres, "cuando venga su padre ya verá lo que hará" pero seguramente cuando llega tiene otras preocupaciones e intereses, lejos para implicarse en la educación y cuidado de sus hijos.

Pareja de abuelos de 70 años viven en una población próxima a Barcelona. Tienen dos hijos y dos nietos pequeños, explican:

Nuestra hija está divorciada con dos hijos pequeños. Trabaja todo el día y hay semanas que viaja por Europa y España por trabajo. Así que... ¿ya sabes quién tiene a los críos, no? Una semana están con la madre que los tenemos nosotros. $Y$ otra están con el padre. Pero no te creas...que cuando están con el padre y tiene trabajo o están enfermos nos los trae a nosotros. Mi marido no se encuentra bien y tiene poca paciencia con ellos. Los nenes quieren jugar todo el día, un rato sí que jugamos con ellos pero todo el rato no podemos, somos grandes y se nos acaba la paciencia. Nosotros no podemos todo el rato y si por ellos fuera... 
El pequeño me llama "mama" y yo le digo que yo soy la "iaia" que la mama es ésta, pero él no lo entiende como pasa mucho más tiempo con nosotros. ;Me da una pena, por ella y por el nene! Porque un hijo no te diga mama y se lo diga a tu madre, tiene que doler mucho. $Y$, ¿qué quieres? si tiene dos añitos y pasa más tiempo conmigo que con ella.

Cuando viene a buscarlos ya son las ocho de la noche. Los niños ya están bañados, cenados y con pijama. Entonces empieza el drama porque los críos no quieren irse a su casa con su madre, dicen que su casa es ésta, la de los "iaios". ¿Qué penita! pero así está montada la vida hoy en día. Muchas veces se van llorando, otras ya se van durmiendo. Entonces es más fácil. Todo el día van de un sitio a otro, no tienen claro ni cuál es su casa.

El pequeño habla muy poco, desde la escuela dicen que le pasa algo pero yo creo que lo que le pasa es la vida que lleva, ya tan pequeño. No es normal que todo el día vaya arriba y abajo. Antes esto no pasaba, ibas a buscar a los hijos al colegio y estabas en el parque con ellos o en casa...Ahora nos quedamos en el parque con ellos y todos son abuelos, no hay ni un padre. Nos ha tocado criar a los hijos y ahora a los nietos... ¿a ver quién se hará cargo de nosotros mañana cuando ya no podamos nosotros...?

Y esto no nos pasa sólo a nosotros que a la salida de la guardería sólo hay abuelos que van a buscar a sus nietos, ya nos hemos hecho amigos con unos cuantos. Está todo el mundo igual, es el ritmo de hoy en día. ¿Qué quieres hacer, si se trabaja todo el día? Y encima están separados... aún gracias... un desastre, un desastre... Y aún gracias que nosotros nos encontramos bien, dentro de lo que cabe y podemos tenerlos y cuidarlos... no es fácil, no es fácil... Menos mal que el otro hijo no tiene hijos, porque sino no sé lo que haríamos... Dice mi marido que él haría las maletas y se iría a Andalucía a vivir, bien lejos (28 de diciembre de 2029).

La informante explica su cotidianidad imbricada con sus nietos. Su hija está divorciada y por motivos de trabajo viaja continuamente y los abuelos son los cuidadores y educadores de los niños. El pequeño de dos años llama a la abuela "mamá", ya que casi todo el tiempo está con ella y su marido; a ella se le rompe el corazón, dice, "¡me da una pena, por ella y por el nene!". La madre recoge sus hijos a las 20:00 horas bañados, cenados y con pijama y ellos no quieren irse de casa, "dicen que su casa es ésta, la de los iaios". Muchas veces los niños se van llorando y le da mucha pena.

El pequeño habla muy poco, tiene poco lenguaje; en las tutorías informaron a su madre que le pasa alguna cosa y lo debería visitarun especialista. En los parques solamente hay abuelas y abuelos; no son ellos solos, es general, "nos ha tocado criar a los hijos y ahora a los nietos...". Todas las familias están igual,el padre y madre delegan el cuidado de sus hijos a los abuelos, entonces hay estas consecuencias. La mujer ha salido de casa sin que el marido haya entrado. La situación de las familias divorciadas todavía es peor, "un desastre, un desastre...". Concluye sus aportaciones preguntando, ¿qué pasará cuando ellos no estén bien o no estén?, ¿quién cuidará de los nietos?...

Finalizadas las aportaciones de los abuelos, en muchas familias los padres no están o de una forma muy precaria. Se consideran el último soporte, eslabón, de una cadena muy frágil que aguanta mientras tengan salud. Continuamos con las aportaciones de los hijos mayores de edad, conocedores de esta realidad social vivida en primera persona ymuchas veces han sufrido las consecuencias. Con su mayoría de edad han podido reflexionar sobre sus vivencias y entorno más próximo. María, es una joven de 19 años, vive en Lleida ciudad y en la actualidad estudia un Ciclo Formativa de Grado Medio, explica:

Casi todo el tiempo he estado en casa de mis abuelos. Mis padres trabajan y mis hermanos y yo nos hemos quedado siempre en casa de nuestros abuelos, por las tardes, los sábados... la casa de mis abuelos es como si fuera mi casa, más que la mía porque he pasado más tiempo allí.

Cuando era pequeña, mi abuela venía muy temprano a nuestra casa y mis padres marchaban a trabajar. Por las tardes nos venía a buscar y llevar al cole. Pocas veces han venido mis padres a buscarnos, quizás algún día que ellos tenían fiesta. Tienen un negocio y primero de todo es el negocio. A veces les digo que quiero más a mis abuelos que a ellos, y entonces se enfadan. Mis abuelos me entienden. Mis padres siempre están enfadados conmigo aunque al final me compran todo lo que les digo. También me gustaría que alguna vez me dijeran que no. Me lo compran para que esté contenta pero a veces me da la sensación que me compran las cosas o me dejan ir a los sitios para tenerme callada y que no les monte el pollo, entonces aún me enfado más. ¡No sé!, es una sensación rara, como de rabia. Hagan lo que hagan 
mis padres no me lo tomo bien. En cambio con mis abuelos es diferente si dicen que no es que no, aunque a veces también los engaño (Entrevista realizada el 15 de noviembre de 2019).

La adolescente explica sus vivencias de niña con sus abuelos principalmente, sus padres siempre estaban trabajando, y ella y sus hermanos estaban en casa de sus abuelos, por las tardes, sábados... Han estado más tiempo en la casa de sus abuelos que en la suya. Piensa en su niñez y tiene la referencia prioritaria de su abuela, en el colegio "pocas veces han venido mis padres a buscarnos". A veces dice a sus padres que "quiero más a mis abuelos que a ellos", no sabemos las circunstancias pero pueden darse situaciones de celos, chantajes...; sus padres, quizás debido a sentirse culpables, "me compran todo los que les digo". María es adulta y realiza reflexiones de sus circunstancias vitales, explica que sus padres le compran cosas para que esté contenta y demostrar cariño y amor. Parece que tenga rabia de sus padres, "hagan lo que hagan mis padres no me lo tomo bien", en cambio, con sus abuelos tiene una relación de confianza, respeto y cariño.

Pau, es una joven de 20 años, vive en Barcelona y en la actualidad está en la Universidad de Lleida, manifiesta:

Vivo con mis padres, soy hijo único. Mis padres tiene un trabajo muy flexible y siempre han sido ellos los que me han llevado a la escuela o por la tarde han estado conmigo o me han llevado a las extraescolares. Tengo mucha suerte, iporque viendo la dinámica familiar de muchos de mis amigos o compañeros de clase!.Tengo muy buena relación con mis padres pero también nos enfadamos de tanto en tanto, como en cualquier casa...Tengo un amigo que lleva una temporada que siempre está en mi casa, tardes, fines de semana... A mis padres no les importa pero a veces le dicen que ya es hora de irse a su casa. ¡Vete ya para tu casa que tus padres estarán preocupados! él ni se inmuta. A él lo han criado sus abuelos. Está muy enfadado con sus padres y no tiene ninguna intención de arreglarlo. No tiene que ser fácil la situación. Hará un par de años que se murió su abuela y unos meses después el abuelo. Fue un palo para él. Siempre, hasta los fines de semana, iba a casa de sus abuelos, allí comían todos, todos los días. Me dice que la situación con sus padres no es buena y que está más cómodo y tranquilo en mi casa. Su hermana hace lo mismo en casa de una amiga, siempre está allí metida. Tienen una situación difícil desde hace tiempo no sé si es porque quienes los criaron fueron los abuelos y ahora ya no están. Dice que su casa es la de los abuelos y ahora sus padres la han puesto a la venta. ¡Está enfadado con el mundo!, ;No me imagino una relación así con mis padres!(Entrevista el 01 de febrero de 2020).

El joven es hijo único y explica sus vivencias de su familia y relaciones con sus padres. Ellos siempre han estado con él, en las entradas y salidas de la escuela, llevándolo a las extraescolares, fiestas de aniversario, vacaciones... Tiene una relación buena con sus padres aunque también hay algunos conflictos, seguramente debido a la adolescencia. Tiene un amigo acogido en su casa, quién "lo han criado sus abuelos", está enfadado con sus padres. Hace unos dos años murió su abuela y después su abuelo, ellos le cuidaban y fue un "palo para él"; seguramente todavía no ha superado el duelo y no tiene el apoyo de sus padres.Su amigo está ";enfadado con el mundo!"; tiene rabia contra sus padres por no ejercer y no darle un vínculo de apego estable, sólido y de confianza.

Miguel de 26 años residente en una localidad cercana de Barcelona, actualmente trabaja, dice:

Actualmente estoy trabajando, hice bachillerato pero lo dejé en segundo curso, más tarde realicé un ciclo formativo de grado medio y después uno de superior. Yo y mi hermana nos hemos criado en casa de mis abuelos, mi padre trabajaba todo el día y mi madre tenía cosas que hacer, total que todo el día estábamos en casa de los abuelos, a las tardes, para comer, los fines de semana... mi casa era la de los abuelos. Incluso nos íbamos con ellos de vacaciones y mis padres se quedaban aquí. La relación que tengo actualmente con mis padres es lejana, fría y de poca confianza; los que realmente me entienden son mis abuelos, pero ellos también se enteran de pocas cosas. A quién le cuento más cosas y tengo más confianza es con mi hermana, ella es tres años más grande que yo y hemos vivido juntos la misma situación. Ella actualmente ya está casada y yo vivo en un piso con estudiantes. Ninguno de los dos tenemos una relación de confianza con nuestros padres. Al principio nos pensábamos que era lo normal en todas las familias pero cuando te vas haciendo mayor y vas comparando con los amigos, te das cuenta que no es normal, que nuestros padres no han hecho de padres, nos han criado nuestros abuelos. Siempre hemos ido un poco perdidos, ¡de aquí para allá!, hemos ido probando cosas porque nadie nos ha guiado, ni a mí ni a mi hermana. Por un lado me ha ido bien porque he hecho lo que me da la gana, he salido siempre hasta la hora que he querido; nadie me decía lo que tenía que hacer, entraba o salía de casa cómo quería... pero por otra parte me siento como vacio; ;una parte de mí me falta!, quizás el vínculo que tendría que tener 
con mis padres y no lo tengo. A veces esto lo he hablado con mi hermana y a ella le pasa exactamente lo mismo, supongo que por eso se fue de casa tan joven a vivir con el novio. iA veces siento rabia!(entrevista realizada el 5 de febrero de 2020).

El entrevistado explica su experiencia vital y la relación con sus padres y abuelos. Se criaron con sus abuelos y siempre estaban con ellos, a la hora de comer, por la tarde, los fines de semanas, vacaciones... Progresivamente se rompió el vínculo con sus padresy se fueron distanciando. Esta relación de confianza la tiene con sus abuelos, ellos lo conocen y comprenden más. Muchas veces habla con su hermana sobre las relaciones con sus padres y tienen las mismas impresiones. Durante su infancia y adolescencia se han sentido en demasiadas veces solos, perdidos, sin una referencia adulta (parental) clara, "siempre hemos ido un poco perdidos, ¡de aquí para allá!, hemos ido probando cosas porque nadie nos ha guiado, ni a mí ni a mi hermana". Reflexión de adulto sobre la libertad que gozaron durante la adolescencia, no tenían control de sus padres, no les supervisaban sus acciones, "he salido siempre hasta la hora que he querido". Al mismo tiempo dice que siente un vacío, "¡una parte de mí me falta!"; está limitado por la falta de un vínculo de apego estable, sólido y de confianza con sus padres. Finaliza sus reflexiones afirmando que siente rabia y frustración por sentirse solo y desarraigado.

Se ha presentado información cuantitativa de la encuesta SHARE, INE y Mémora destacando como la participación de los abuelos para cuidar a los nietos es una realidad significativa en España y también en Cataluña. En muchas familias hay un cuidado intensivo hacia los menores, teniendo consecuencias para los abuelos, se hace referencia a los "abuelos esclavos" pero también hacia los niños, limitando su desarrollo psicológico y educativo por la construcción de un vínculo de apego deficiente.

\section{Conclusiones}

El artículo ha pretendido mostrar una realidad social y cultural conocida por los ciudadanos pero poco estudiada por las ciencias sociales. Se han presentados datos cuantitativos del Instituto Nacional de Estadística (INE), Encuesta de Salud, Envejecimiento y Jubilación de Europa (SHARE) y la encuesta Mémora. La encuesta SHARE del año 2016 para España destaca que el $25 \%$ de los abuelos cuida cada día una media de siete horas diarias a sus nietos, también durante los fines de semana. La encuesta Mémora, en Cataluña, concluye que casi el 50\% de las personas mayores dicen que existe el concepto del "abuelo esclavo". En la actualidad todavía no se ha superado totalmente la crisis económica y muchas familias tienen a los abuelos como el último sostén económico y psicológico (Mari-Klose et al., 2015). En las familias españolas y catalanas ha habido cambios destacados, transformando dinámicas y rolesentre sus miembros. Elzo (2006 y 2008) explica que se ha producido un alejamiento de los padres en la educación de sus hijos, las mujeres han salido de casa y el hombre no ha entrado y el hogar ha quedado huérfano. Este vacío ha sido llenado por los abuelos cuidadores de los nietos, quienes son en muchos casos "padres sustitutos" pero con las limitaciones propias de la edad. Tiene consecuencias para el desarrollo social y pedagógico de los infantes: pérdida del sentido de la autoridad, límites y reglas difusas, confusión de roles, menor autoestima... (Rald Philipp, 2007).

Las aportaciones de los entrevistados han resultado iluminadoras para comprender la dimensión social y educativa de los abuelos cuidadores. Paula, maestra de infantil, explica que los abuelos tienen dificultades para imponer límites, reglas y rutinas a sus nietos. Los mayores no tienen las fuerzas, interés o capacidades necesarias para educarlos en muchos casos; aunque dice que ella necesita de su ayuda. José, maestro de primaria, dice que los padres no están y los abuelos están desbordados; muchos alumnos tienen dificultades para regular su comportamiento sin un trastorno mental, solamente son causas sociales y familiares. Con la llegada de la adolescencia, estos jóvenes han perdido el vínculo con su familia (padres) y su referencia principal son el grupo de iguales. Mireia, maestra de p-3, habla sobre los niños que tienen dificultades para relacionarse, parecen autistas pero no lo son. Los abuelos utilizan el señuelo de los móviles para realizar tareas necesarias con los nietos: comer, ducharlos, cambiarlos...; los define como "niños pantalla". 
Las abuelas realizan reflexiones interesantes, María de 72 años dice que no tiene tiempo para aburrirse ni para ir a la peluquería. Cada día está con sus nietos hasta las 20:00 horas, listos para llevarlos sus padres directamente a la cama. Cuando tiene algún conflicto con los nietos dice "cuando venga tu padre ya verá lo que hará", aunque seguramente cuando llega tiene otras preocupaciones e intereses y no se trata el tema. La pareja de abuelos de Barcelona explican que su nieto le dice "mama" y ella responde que no es la mama sino la "iaia"; le da mucha pena por la madre y el niño. En referencia a los hijos, María explica que quiere más a sus abuelos que a sus padres. Sus padres le compran cosas para que esté contenta y demostrar su cariño y amor. Miguel dice que durante su infancia y adolescencia se han sentido muchas veces solos, perdidos, sin una referencia adulta (parental) clara. Siente un vacío interior, está limitado por unvínculo de apego deficiente.

Seguidamente se presentan algunas posibles futuras líneas de investigación y limitaciones. Se podrían realizar análisis más pormenorizados, entrar en detalle de diferentes características de las familias, buscar relaciones por clase social, tipologías familiares, por entornos (rural, urbano...)...Se podría realizar una comparativa por países, comunidades autónomas...; realizar estudios longitudinales...; se podría profundizar en las historias de vida de los padres (en la investigación no se han contemplado), analizar sus expectativas, proyectos... familiares y propios. También tener en cuenta posibles diferencias entre número de nietos y su género y el número de los abuelos (si están los cuatro o cuantos colaboran). En todo caso, la irrupción de los abuelos cuidadores intensivos hacia sus nietos requiere un abordaje amplio desde diferentes disciplinas.

Para ir finalizando, en los últimos años las sociedades avanzadas se han transformado radicalmente en múltiples dimensiones. Un cambio acaecido significativo ha sido el cuidado intensivo de los abuelos hacia los menores, teniendo consecuencias para la vida de los mayores pero también para los infantes, limitando en muchos casos su desarrollo social y educativo. Se requiere analizar la problemática en toda su profundidad y aplicar políticas sociales y educativas para no discriminar determinados niños por cuestiones principalmente económicas o disponibilidad parental. Se debería facilitar la presencia intensa de los padres y madres para el cuidado y educación de sus hijos en las mejores y más amplias posibilidades. Se puede afirmar que todavía existen escasos estudios sobre la temática abordada y se debería analizar con más profundidad en diferentes contextos.

\section{Referencies}

Aguayo, C. y Nass, L. (2013). Estereotipos sociales como amenaza a la inserción de los adultos mayores. Revisión narrativa. Journal of Oral research. 2(3): 145-152. https://doi.org/10.17126/joralres.2013.032. Consultado el 01.03.2020.

Ander, E. E. (2000). Métodos y técnicas de investigación social. Lumen, Buenos Aires (Argentina).

Allepuz, R. y Rosell, M. J. (2014). Anatomía de la pobreza a Catalunya. Ed. Pagés, Lleida (España).

Arpino, B. y Bordone, V. (2017). Regular provision of grandchild care and participation in social activities. Review of economics of the Household. 15: 135-174. https://doi.org/10.1007/s11150-016-9322-4.

Arpino, B.; Bordone, V. y Balbo, N. (2018). Grandparenting, education and subjective well-being of older Europeans. European Journal of Ageing. 15: 251263. https://doi.org/10.1007/s10433-018-0467-2.

Badenes, N. y López, M. T. (2011). Doble dependencia. Abuelos que cuidan nietos en España. Zerbitzuan. 49: 107-125. http://www.zerbitzuan.net/documentos/zerbitzuan/Doble\%20dependencia.pdf.

Beavoir, S. (1983). La vejez. Edhasa, Barcelona (España).

Bowlby, J. (1998). El apego. Paidós, Barcelona (España).

Bowlby, J. (2006). Vínculos efectivos: formación, desarrollo y pérdida. Morata, Madrid (España).

Bowlby, J. (2009). La separación afectiva. Paidós, Barcelona (España).

Caballero, M. (2015). Transferencias ambientales intergeneracionales: un análisis sobre abuelos y nietos. Tesis doctoral de la Universidad Pontificia de Salamanca. https://dialnet.unirioja.es/servlet/tesis?codigo $=54084$.

Elzo, J. (2006). Los jóvenes y la felicidad: ¿Dónde la buscan? ¿Dónde la encuentran?. PPC, Madrid (España). 
Research, Society and Development, v. 11, n. 2, e12511225686, 2022

Elzo, J. (2008). La voz de los adolescentes. PPC, Madrid (España).

Fernández, M. D. (2016). ¿Quién me lleva a la escuela...? Tiempos de entrada y salida. Infancia: Educar de 0 a 6 años, 158: 2-3. https://dialnet.unirioja.es/servlet/articulo?codigo $=5603011$

León, A.; Hernándz, L. y Rodríguez, C. (2016). Un análisis del vínculo abuelos-nietos-adolescentes reflexión sobre la transmisión generacional. Revista Katálysis, 19 (2): 251-259. https://doi.org/10.1590/1414-49802016.00200010.

Luna, S.; Ramos, P. y Rivera De Los Santos, F. (2016). Afrontamiento, estrés y salud en abuelas cuidadoras de familias ascendentes y descendentes. Estudios de Psicología, 37(1): 101-114. https://doi.org/10.1080/02109395.2015.1122435.

Mari-Klose, M. y Escapa, S. (2015). Solidaridad intergeneracional en época de crisis: ¿mito o realidad? .Panorama Social, 22: 61-78. http://diposit.ub.edu/dspace/bitstream/2445/69077/1/656567.pdf.

Mejías, I. y Ballesteros, J. (2011). Abuelos y abuelas... para todo: percepciones en torno a la educación y el cuidado de los nietos. Madrid: FAD https://www.fad.es/wp-content/uploads/2019/05/Abuelos-completo.pdf.

Mémora. (2018). Enquesta sobre les àvies i avis cuidadors dels seus néts i nétes. Grup Mémora, Barcelona (España)

Radl Philipp, R. (2007). Roles de género y vejez: las relaciones familiares entre abuelas, abuelos, nietas y nietos en la actualidad. En La sociología y los nuevos retos. A socioloxía e os novos retos: IV Congreso Astur-galaico de Socioloxía, A Coruña (España), 23-24 de marzo de 2007. https://dialnet.unirioja.es/servlet/articulo?codigo $=2738447$.

Ricis, J. (2017). "Un vínculo especial, abuelo-nieto: una relación de confianza". Tesis doctoral de la Universidad de Extremadura. https://dialnet.unirioja.es/servlet/tesis?codigo=122003

Share. (2016). Encuesta de salud, envejecimiento y jubilación en Europa. http://www.share-project.org/home0.html.

Stake, R. (1998). Investigación con estudios de casos. Morata, Madrid (España).

Tahull, J. (2016). La compleja transición de los adolescentes hacia la vida adulta. Revista antropología experimental. 16: 27-44 https://doi.org/10.17561/rae.v0i16.285.

Tahull, J. y Montero, I. (2019). La transformación de las familias. La irrupción del hijo único. Revista Miscelánea Comillas. 77 (151): 317-340. https://revistaselectronicas.ujaen.es/index.php/rae/article/view/2853.

Tahull, J. y Montero, I. (2020). ¿La jornada intensiva en los centros educativos produce situaciones de desigualdad socioeducativa entre los alumnos? Revista Tendencias Pedagógicas. 35: 74-89. http://dx.doi.org/10.15366/tp2020.35.007. 